\title{
Monitoring of QTc interval in patients with COVID-19. First experience with a portable ECG-recording device
}

\author{
María Abellas-Sequeiros ${ }^{1}$, Cristina Lozano-Granero ${ }^{1}$, Cristina García-Sebastián ${ }^{1}$, \\ Eduardo Franco-Díez ${ }^{1}$, Antonio Hernández-Madrid ${ }^{1}$, Javier Moreno-Planas ${ }^{1}$, \\ Jaime Masjuan-Vallejo ${ }^{2}$, Marcelo Sanmartín-Fernández ${ }^{1}$, Jose Luis Zamorano-Gómez ${ }^{1}$ \\ ${ }^{1}$ Cardiology Department, Hospital Ramón y Cajal, Madrid, Spain \\ ${ }^{2}$ Neurology Deapartment, Hospital Ramón y Cajal, Madrid, Spain
}

This article is accompanied

by the editorial on page 358

Treatment of coronavirus disease 2019 (COVID-19), as a new entity lacking sufficient evidence-based pharmacotherapy, was initially based in drugs with in-vitro activity against severe acute respiratory syndrome coronavirus 2 (SARS-CoV-2) such as hydroxychloroquine, azithromycin and lopinavir/ritonavir. Each of these drugs is known to prolong QT interval [1-3]. This phenomenon is of utmost importance, as it is associated with early after-depolarizations, which can generate shortcoupled premature action potentials that lead to ventricular fibrillation and sudden cardiac death [4]. Therefore, it seems mandatory to implement monitoring systems, in a scenario where the use of portable electrocardiographic-recording devices could be useful.

This is an observational prospective study in a tertiary hospital. Patients hospitalized for confirmed SARS-CoV-2 pneumonia and receiving specific treatment with either hydroxychloroquine, azithromycin or lopinavir/ritonavir (or combination) were included. Patients were classified into three groups: group 1 received one drug, group 2 received a combination of two drugs and group 3 received a combination of three drugs. Patients in which the electrocardiogram (ECG) tracing obtained with the mobile ECG recording device was of poor quality were excluded from the study.
Clinical information and 12-lead ECG recordings were collected. Baseline QT interval was measured in limb leads using the admission-ECG. The patients received pharmacological treatment according to center-specific guidelines. Verbal informed consent was obtained from patients and approval from the ethics committee of our center was received. A Kardia-Mobile $6 \mathrm{~L}^{\circledR}$ (AliveCor, Inc., Mountain View, California) was used for ECG monitoring. This device, approved by the Food and Drug Administration for QT interval monitoring, consists of a lightweight 3-electrode hardware capable of registering a 6-lead ECG and a smartphone software application. ECGs were recorded periodically with the physicians' criteria. A subset of patients at early discharge were offered one device to daily self-monitoring. Corrected QT (QTc) interval was calculated using the Bazett formula. Primary outcome was to describe the usefulness of telemonitoring in COVID-19 patients for management of QT-prolonging drugs by assessing the proportion of patients with significant ECG changes that imply a change in management. Secondary outcome was to evaluate the inter-observer reproducibility of QT interval quantification using this gadget.

The Shapiro-Wilk test was used to assess normality in continuous variables. Continuous variables were compared using the Wilcoxon or Kruskal-Wallis tests, as appropriate. The Wilcoxon signed-rank test was used for paired measurements. Bilateral p values $<0.05$ were considered statistically significant. To test inter-observer vari-

Address for correspondence: Cristina Lozano-Granero, MD, Cardiology Department, Hospital Ramón y Cajal, Ctra, Colmenar Viejo, km 9100, 28034, Madrid, Spain, tel: +34 678-69-00-25, e-mail: cristina.lozano@hotmail.es

This article is available in open access under Creative Common Attribution-Non-Commercial-No Derivatives 4.0 International (CC BY-NC-ND 4.0) license, allowing to download articles and share them with others as long as they credit the authors and the publisher, but without permission to change them in any way or use them commercially. 
Table 1. Clinical characteristics and QTc interval evolution in the three treatment groups.

\begin{tabular}{|c|c|c|c|c|}
\hline & $\begin{array}{c}\text { Group 1 } \\
\text { (one drug) } \\
\mathbf{N}=\mathbf{9}(13.0 \%)\end{array}$ & $\begin{array}{c}\text { Group 2 } \\
\text { (two drugs) } \\
N=37(53.6 \%)\end{array}$ & $\begin{array}{c}\text { Group } 3 \\
\text { (three drugs) } \\
N=23(33.3 \%)\end{array}$ & $\mathbf{P}$ \\
\hline \multicolumn{5}{|l|}{ Clinical characteristics } \\
\hline Age [years] & $55.0 \pm 18.3$ & $66.0 \pm 16.2$ & $58.0 \pm 15.8$ & 0.248 \\
\hline Male sex & $6(66.7 \%)$ & $25(67.6 \%)$ & $18(78.3 \%)$ & 0.643 \\
\hline Dyslipidemia & $5(55.6 \%)$ & $9(24.3 \%)$ & $7(30.4 \%)$ & 0.749 \\
\hline Diabetes & $7(77.8 \%)$ & $4(10.8 \%)$ & $5(21.7 \%)$ & 0.525 \\
\hline Hypertension & $3(33.3 \%)$ & $16(43.2 \%)$ & $8(34.8 \%)$ & 0.387 \\
\hline Previous cardiopathy & $6(66.7 \%)$ & $11(29.7 \%)$ & $3(13.0 \%)$ & 0.305 \\
\hline COPD & $7(77.8 \%)$ & $6(16.2 \%)$ & $1(8.7 \%)$ & 0.679 \\
\hline Atrial fibrillation & $1(11.1 \%)$ & $3(8.1 \%)$ & 0 & 0.297 \\
\hline Mortality & 0 & $4(10.8 \%)$ & 0 & 0.159 \\
\hline \multicolumn{5}{|l|}{ QTc interval } \\
\hline QTc interval at admission [ms] & $340.0[320.0-350.0]$ & $408.0[377.2-423.5]$ & $394.0[373.0-422.5]$ & 0.039 \\
\hline Maximal QTc interval [ms] & $418.0[384.5-460.5]$ & $426.0[412.0-450.0]$ & $435.0[405.0-450.0]$ & 0.085 \\
\hline QTc $>450 \mathrm{~ms}$ & $3(33.3 \%)$ & $9(24.3 \%)$ & $6(26.1 \%)$ & 0.859 \\
\hline$\Delta \mathrm{QTc}>60 \mathrm{~ms}$ & $1(11.1 \%)$ & $4(15.4 \%)$ & $3(9.7 \%)$ & 0.818 \\
\hline
\end{tabular}

Qualitative variables are shown as number (percentage); quantitative variables are shown as mean \pm standard deviation or median [interquartile range], as appropriate; COPD — chronic obstructive pulmonary disease

ability of QTc measurements, 120 random ECGs were analysed by two independent cardiologists. Intraclass correlation coefficient was obtained (two-way random, average measures, absolute agreement). Statistical analysis was performed using SPSS (IBM Inc., Armonk, NY).

A total of 70 patients fulfilled criteria. Tracings obtained with the portable device were of sufficient quality to provide an accurate QT interval measurement in 69 of them (98.6\%). Mean follow-up was $6.2 \pm 8.4$ days. Characteristics of the different groups are shown in Table 1. An increase in QTc interval was observed in all treatment groups, being non-significant in group 1 (group 1: 340 [320.0-350.0] vs. 418 [384.5-460.5], $\mathrm{p}=0.109$ ). Significance was reached in both group $2(408$ [377.2-423.5] vs. 426 [412.0-450.0], $\mathrm{p}=0.002)$ and group 3 (394 [373.0-422.5] vs. 435 [405.0-450.0], $\mathrm{p}=0.001)$. Eighteen $(25.7 \%)$ patients developed a QTc interval > $450 \mathrm{~ms}$. These patients were significantly older $(67.5 \pm 14.9$ vs. $55.0 \pm 16.0$ years, $\mathrm{p}=0.004$ ) and were more likely diagnosed of chronic obstructive pulmonary disease $(33.3 \%$ vs. $5.9 \%, \mathrm{p}=0.009)$ and previous cardiopathy $(50 \%$ vs. $13.7 \%, \mathrm{p}=0.007)$. Taking into consideration the information given by the ECG monitoring devices, physicians adopted a different approach in the management of $12(17.4 \%)$ patients. Treatment was modified in 9 (13\%) patients because of prolongation of the QTc interval (1 of them also developed first degree atrioventricular block, with a PR interval up to $280 \mathrm{~ms}) ; 2$ (2.9\%) patients required monitoring intensification ( 1 of them because of first degree atrioventricular block and the other because of prolongation of the QTc interval) and anticoagulation was started in one patient because of atrial fibrillation diagnosis.

The subgroup of 16 patients who were given a recorder to continue daily monitoring experienced also significant prolongation of the QTc interval (381.0 [372.0-401.5] at admission vs. 424.0 [406.0-436.7] at peak, $\mathrm{p}=0.002)$, with mean time to reach the maximum QTc: $2 \pm 1.8$ days). By the end of the monitoring phase, QTc intervals were shorter than those at admission (381.0 [372.0-401.5] vs. 350.0 [334.2-369.0]; $\mathrm{p}=0.019$ ).

Inter-observer intraclass correlation coefficient was $0.824,95 \%$ confidence interval 0.733 -0.882 (good agreement).

Herein, is presented one of the first series of patients both hospitalized [5, 6] and discharged with COVID-19 with electrocardiographic surveillance using a portable ECG recorder [7]. The device proved to be useful for ECG monitoring in these patients, detecting ECG anomalies of enough importance to promote a change in management in 
$17.4 \%$ of them. These anomalies consisted not only in QTc interval prolongation, but also in PR interval prolongation and atrial arrhythmias. These small, light gadgets allow physicians to quickly perform an ECG to a high number of patients, including the monitoring of outpatients. These characteristics were determinant to ensure safe management in the first wave of the COVID-19 pandemic, when an enormous number of patients overtook available resources.

The intraclass correlation coefficient points a good agreement in the measurements of QTC interval using these portable recorders, supporting the solidness of this handheld device. Once confirmed the value and the reliability of these devices, ECG portable recorders are called to be part of the workaday armamentarium in our hospitals.

\section{Conflict of interest: None declared}

\section{References}

1. Ray WA, Murray KT, Hall K, et al. Azithromycin and the risk of cardiovascular death. N Engl J Med. 2012; 366(20): 1881-1890, doi: 10.1056/NEJMoa1003833, indexed in Pubmed: 22591294.
2. Chen CY, Wang FL, Lin CC. Chronic hydroxychloroquine use associated with QT prolongation and refractory ventricular arrhythmia. Clin Toxicol (Phila). 2006; 44(2): 173-175, doi: 10.1080/15563650500514558, indexed in Pubmed: 16615675.

3. Anson B, Weaver J, Ackerman M, et al. Blockade of HERG channels by HIV protease inhibitors. Lancet. 2005; 365(9460): 682-686, doi: 10.1016/s0140-6736(05)70936-3.

4. Straus SM, Kors JA, De Bruin ML, et al. Prolonged QTc interval and risk of sudden cardiac death in a population of older adults. J Am Coll Cardiol. 2006; 47(2): 362-367, doi: 10.1016/j. jacc.2005.08.067, indexed in Pubmed: 16412861.

5. Chang D, Saleh M, Gabriels J, et al. Inpatient use of ambulatory telemetry monitors for COVID-19 patients treated with hydroxychloroquine and/or azithromycin. J Am Coll Cardiol. 2020; 75(23): 2992-2993, doi: 10.1016/j.jacc.2020.04.032, indexed in Pubmed: 32330546.

6. Guerrero LR, Ongay AG, Álvarez ÁC, et al. Protocolo de manejo hospitalario de alteraciones electrocardiográficas en pacientes con COVID-19 con un sistema portátil vinculado a smartphone. REC: CardioClinics. 2020; 55(3): 192-195, doi: 10.1016/j. rccl.2020.05.006.

7. Strik M, Caillol T, Ramirez FD, et al. Validating QT-interval measurement using the apple watch ECG to enable remote monitoring during the COVID-19 pandemic. Circulation. 2020; 142(4): 416-418, doi: 10.1161/CIRCULATIONAHA.120.048253, indexed in Pubmed: 32478565. 